\section{Formas de governo e complementaridade entre a administração estatal e seus administrados: reflexões a partir de um serviço para homens autores de violência doméstica'}

\author{
Paulo Victor Leite Lopes \\ Universidade Federal do Rio Grande do Norte | Natal, RN, Brasil \\ paulovleitelopes@gmail.com \\ ORCID: https://orcid.org/0000-0001-9589-2248
}

RESUMO

Esse artigo reflete como determinadas formas de governo, apreendidas etnograficamente por meio de minha inserção como pesquisador em uma instância administrativa na Baixada Fluminense do Rio de Janeiro, são (re)elaboradas na atuação de um "serviço" destinado a "homens autores de violência doméstica". Nesse sentido, trata-se de uma investigação acerca de processos de formação de Estado, cuja ênfase encontra-se nas práticas, dinâmicas e interações estabelecidas cotidianamente por administradores - "os técnicos" - e administrados - "os homens"-, bem como entre diferentes instâncias e dispositivos estatais. Procuro compreender tanto a produção contínua do Estado "em ato", privilegiando tanto as dinâmicas constitutivas dos modos de fazer da administração, quanto os modos de subjetivação que, a partir de uma série de constrangimentos conduzidos pelas formas específicas de gestão a que estão submetidos, são operacionalizados pelos sujeitos atendidos pela instância etnografada.

\section{FORMS OF GOVERNMENT AND COMPLEMENTARITY BETWEEN STATE ADMINISTRATION AND ITS} ADMINISTRATED: REFLEXIONS ON A SERVICE FOR MEN WHO COMMIT DOMESTIC VIOLENCE
DOI

http://DX.DOI.ORG/

$10.11606 / 1678-9857$

RA. 2020.189657

1| A elaboração desse artigo, baseado em um dos capítulos da minha tese de doutorado, se beneficia das discussões mantidas no CT 11 - Cênero, sexualidade e direitos, coordenado por Heloísa Buarque de Almeida (USP) e Regina Facchini (UNICAMP), no VI ENADIR, 26 a 29 de agosto, como também das trocas mantidas na edição do Colóquios CLAM/LIDIS de setembro de 2019, coordenado por Amaral Arévalo (UERJ). Agradeço às/o organizador/as aqui indicadas/o e também a demais participantes dos dois encontros pelos comentários feitos ao meu trabalho.
PALAVRAS-CHAVE

Violência doméstica contra a mulher, estado, grupos reflexivos para homens autores de violência doméstica, etnografia

\section{KEYWORDS}

Domestic violence against women, state reflective groups for men who commit domestic violence, ethnography 
Ao longo de um ano, entre 2013 e 2014, acompanhei de três a quatro vezes por semana uma instância administrativa que procurava "enfrentar a violência doméstica" a partir de uma atuação com os homens. O foco principal daqueles profissionais (uma psicóloga, um advogado, um coordenador e um assistente administrativo) estava na realização de "grupos reflexivos" com "homens autores de violência doméstica e familiar contra a mulher". Esses sujeitos, em sua maioria de camada popular, com profissões que exigiam pouca qualificação e recebiam baixa remuneração, participavam dos "encontros" em razão de decisão judicial. ${ }^{2}$

A adesão aos "grupos" envolvia algumas ações anteriores e posteriores a sua realização. Antes do "primeiro encontro do grupo", havia o "acolhimento", isto é, uma espécie de entrevista-conversa entre o sujeito e um membro da "equipe". Nessa ocasião, um dos "técnicos" (a psicóloga, o advogado ou o coordenador) se apresentava, falava do serviço e preenchia um questionário com informações sobre o indivíduo, aspectos da sua vida familiar, sobre consumo de álcool e drogas e a respeito do processo que respondia/respondeu. Após esse momento, o sujeito esperaria o início do grupo para o qual foi encaminhado - que ocorriam terça, quarta ou quinta-feira, entre 10h/12h ou 14/16h, no Juizado de Violência Doméstica e Familiar Contra a Mulher do município, no centro da cidade, ou ainda na própria sede do serviço, localizado em um bairro distante do centro, ao lado de relevante prédio da gestão municipal e de uma importante via de acesso da Região Metropolitana do Rio de Janeiro.

Cada encontro tinha cerca de duas horas e funcionava, em geral, a partir de uma "dinâmica" de grupo ou exibição de um vídeo que, em seguida, passava a ser discutido por todos. Para encerrar, uma nova atividade que servia como ponto de partida para que um dos técnicos recuperasse aspectos debatidos no dia. Os grupos, com periodicidade quinzenal, somavam um total de oito encontros - sendo facultada a ausência de dois dias nesses quatro meses. Passados noventa dias da conclusão dos oito grupos, os homens deveriam voltar para a realização do "encontro de avaliação" - onde era preenchido um questionário que abordava a "condução" dos encontros, a "atuação" da equipe, o engajamento deles próprios e seus "aprendizados".

Além de encontros específicos que observei no início e ao término do trabalho de campo, isto é, grupos que já estavam em andamento quando me aproximei do serviço ou que continuaram quando encerrei as minhas atividades mais sistemáticas, pude acompanhar a integralidade dos oito encontros, mais o de avaliação, de seis grupos reflexivos para a etnografia que desenvolvi. Em geral, mantinha-me em silêncio durante os debates, realizando anotações apenas quando deixava o local onde os trabalhos eram realizados. Para a minha reflexão, ainda fiz uso de amplo material documental produzido e disponibilizado pela equipe, de informações obtidas através de observação participante fora dos encontros dos grupos, e da (re)escuta das gravações que realizei nos grupos - mediante autorização dada pela/os profissional/is e participantes, após a minha apresentação pessoal, dos interesses da pesquisa e da demanda de registro.
2 | Informações obtidas através dos relatos e apresentações realizadas pelos homens ao longos dos encontros e grupos, como também em razão do acesso e análise do material documental produzido pela equipe a respeito dos sujeitos e de seus atendimentos. Além das informações disponibilizadas no próximo parágrafo, reflito sobre esses documentos em Lopes (2016) 
Esse artigo procura refletir sobre como determinadas formas de governo, apreendidas etnograficamente através de minha inserção nessa instância administrativa na Baixada Fluminense do Rio de Janeiro, são elaboradas no cotidiano de um "serviço" destinado a "homens autores de violência doméstica". Nesse sentido, trata-se de uma investigação acerca de processos de formação de Estado, cuja ênfase encontra-se nas práticas, dinâmicas e interações estabelecidas cotidianamente por administradores"os técnicos" - e administrados - "os homens"-, bem como entre diferentes instâncias e dispositivos estatais. Procuro compreender tanto a produção contínua do Estado "em ato", privilegiando as dinâmicas constitutivas dos modos de fazer da administração (Teixeira e Souza Lima, 2010, entre outros), quanto os modos de subjetivação que, a partir de uma série de constrangimentos conduzidos pelas formas específicas de gestão a que estão submetidos, são operacionalizados pelos sujeitos atendidos pela instância etnografada - que chamarei aqui de Serviço para Homens (SPH).

Trago, para tanto, dois aspectos fundamentais dos "grupos reflexivos para homens autores de violência doméstica e familiar contra a mulher", um dos locais onde conduzi a minha observação: 1) sugiro o delineamento de elementos que podem ser tomados como constitutivos dos sentimentos de empatia, pertencimento e coletividade, indicando como estes entrelaçam seus participantes e tornam possível a elaboração de narrativas comuns em torno de si e das suas experiências de violência; 2) diante disso, desenvolvo uma apreensão a respeito da manifestação de técnicas de poder específicas no interior daqueles "encontros", em que a produção e manutenção de hierarquias entre administrados e administradores tornam-se evidentes.

Nessa direção, acredito que por meio da caracterização das relações mantidas entre os profissionais e os atendidos será possível apontar a dimensão fundamentalmente afetiva-emocional que caracteriza não apenas a convivência daqueles sujeitos, mas também concepções fundamentais em torno dessa modalidade de intervenção, suas técnicas e objetivos. O exame dessa ordem afetiva deve ser apreendido ou remetido a um escopo mais amplo de atuação do poder tutelar como forma característica de atuação/distribuição/reconhecimento de direitos no âmbito do estado brasileiro (Pacheco de Oliveira, 1989, Souza Lima, 1995, Vianna, 2002). Em razão desse recorte conferido ao artigo, portanto, não aprofundarei no debate acerca das questões da violência doméstica e elaborações específicas sobre gênero, também presentes ao longo dos encontros dos grupos e alvo de minha reflexão em outro espaço (Lopes, 2016), privilegiando os 'enquadramentos administrativos' que indiquei acima e que são objeto dessa análise³.

\section{OS GRUPOS REFLEXIVOS ${ }^{4}$}

Durante o período do meu trabalho de campo, o SPH contava com quatro funcionários diretamente sublocados para a prestação dos serviços (como eles se

3 | Caso a/e/o leitor/a/e tenha interesse nesse debate, consultar Lopes (2016).

4 |Apesar de origem histórica anterior, no Brasil os "grupos reflexivos" se multiplicaram e ganharam grande visibilidade após a promulgação da Lei Maria da Penha que prevê, nos artigos 35 e 45, respectivamente, "centros de educação e de reabilitação para os agressores" ou "programas de recuperação e reeducação". Como tais artigos e a minha apresentação já anunciam, há uma série de disputas e divergências em torno dessa modalidade de intervenção evidenciadas, por exemplo, nas nomeações: "grupos reflexivos", "centros de educação", "de reeducação", "de reabilitação" ou "de recuperação". De maneira bem sintética, as divergências relacionam-se à ênfase que se deseja dar

à condução dos grupos.

Em outra oportunidade, Fabiane Leite e eu (2013), como outras/os autoras/es da publicação (Lopes e Leite, 2013), apontamos algumas das principais perspectivas que identificamos em campo: alguns identificados mais com um caráter "pedagógico/educativo", outros "terapêuticos" e ainda havia os "reflexivos". Para saber mais sobre esses debates, além das referências já citadas, consultar Nascimento (2001), Lima e Buchele (2011) e Beiras; Nascimento e Incrocci (2019). 
apresentavam: um coordenador, um advogado, uma psicóloga e um assistente administrativo). ${ }^{5}$ Com pouco mais de quarenta anos, Pedro tem três filhas, é evangélico, graduando em psicologia e estava divorciado durante o período mais intenso da pesquisa. Me contou que sua aproximação com a temática se deu como estagiário de outras duas iniciativas do mesmo tipo. A partir das conversas que mantive com Pedro, bem como das diversas situações em que pude observá-lo em cena, é possível identificar a sua intimidade com as temáticas do campo que tem os homens como sujeito principal de atuação e intervenção. O próprio modo como apresenta o SPH, a sua missão e esferas de atuação, evidencia a sua proximidade com as principais ênfases dos discursos desse campo ${ }^{6}$ : destaca "a necessidade de trabalhar a prevenção", o "enfrentamento da violência doméstica que já aconteceu" e a "construção de outras masculinidades" - sobre esse último aspecto, em geral, refere-se a transformações no modo como os sujeitos passam a (ou deixam de) se relacionar com outras pessoas, em especial, com os familiares, mas também ao que se refere a si mesmo, sobretudo o cuidado que mantêm com a própria saúde.

João Carlos, Joca ou, como se apresentava com regularidade, o "Doutor João Carlos", é advogado, funcionário público e tinha quase sessenta anos de idade durante a pesquisa. Casado, pai de um filho de vinte e um anos, é morador de outro município da Região Metropolitana do Rio de Janeiro. É funcionário da prefeitura há quase trinta anos. Atuava há três anos no SPH e, nos seus próprios termos, estava "esperando a sua aposentadoria". Embora "goste do espiritismo", se identifica como católico e frequenta, eventualmente, uma paróquia em seu município - a sua esposa "não gosta do espiritismo" e nem da frequência dele nas celebrações dessa religião. Além de ser funcionário público do município, possui um pequeno número de "causas" que advoga individualmente - pretende, após se aposentar, montar novamente um escritório. Joca, ao longo do trabalho de campo, sempre comentava que estava satisfeito no $\mathrm{SPH}$, que só estava esperando se aposentar etc. Segundo ele, gosta muito de estar ali, pois "se dá bem com a equipe", o "trabalho é mais leve" e "gosto do que faço".

Débora, "a psicóloga do SPH", é casada, católica, tem 44 anos e mora em um bairro de classe média do subúrbio carioca. Antes do SPH, atuou em diferentes espaços da gestão da violência doméstica naquele município. Mesmo que a sua transferência entre os órgãos da prefeitura para o SPH tenha ocorrido contra a sua vontade, Débora sempre diz que gosta de trabalhar no SPH e "com os homens". Assim como Joca, considera que o trabalho feito é exitoso e se diz "realizada" com o mesmo - gosta de citar um ou outro homem em que identifica "progresso". Contudo, tem reclamado bastante a respeito de algumas "condições de trabalho". Esse aspecto é interessante, pois, algumas vezes, Débora ressaltava a importância de algum trabalho que fosse voltado para eles, os técnicos. Revelava que as situações de violência que deram origem aos processos e "a agressividade dos homens que chegam revoltados com a justiça, com o juiz, com a polícia e com a Maria da Penha", mas também outras questões da $\mathbf{5}$ | Considerando os limites do espaço e a pertinência para análise aqui empreendida, omitirei a apresentação de Roberto, assistente administrativo do $\mathrm{SPH}$. Caso a/o leitor/a tenha interesse, consultar Lopes (2016).

6| Para saber mais sobre o campo, seus temas, articulações e diferenças, consultar, entre outras/os, Lima e Buchele (2011), Lopes e Leite (2013), Lopes (2016; 2021) e Beiras; Nascimento e Incrocci (2019). 
rotina que considerava extenuantes, produziam grande "desgaste emocional", mas que, no entanto, não encontravam nenhum canal de escoamento.

Ao longo trabalho de campo, pude observar que desde o primeiro contato entre administradores e administrados, isto é, no "acolhimento", tendo continuidade ao longos dos encontros dos grupos e após o término deles, na "avaliação", determinado esforço dos técnicos por produzir uma imagem acerca do $\mathrm{SPH}$, seus funcionários e dinâmicas. Tratava-se de um movimento da equipe em antecipar-se diante da resistência (efetiva e presumida) apresentada pelos homens ao "encaminhamento" e participação do grupo, como ressaltado acima, mas também uma aposta que mantinham acerca da sua atuação profissional.7 No final do primeiro encontro de um dos grupos, após os homens relatarem as situações que os conduziram até ali, Débora explicitou os fundamentos e sentidos do trabalho que executam:

Gente, diante desses fatos, como eu falei pra vocês, tem uma riqueza de informações, de histórias pra contar. Eu sei que todos ficam um pouco revoltados com tudo o que aconteceu. (...) E, como eu disse, num encontro só não dá, nós estamos já quase que um pouquinho no limite [do horário], mas é preciso que nós possamos trazer pra vocês o que nós vamos fazer daqui pra frente. (...) Aquilo que eu falei pra vocês, aquela frase, eu vou trazer um texto: "não façam julgamentos precipitados". Porque o que nós estamos fazendo aqui, mais uma vez repetindo, não é pra punir, mas é pra ajudar, pra orientar, é pra não deixar que aconteça novamente. Por quê? Nós falamos muito sobre um ciclo da violência, se persistir, esse ciclo vai continuar, é que nem uma bola de neve, se você não tiver nenhuma freada, não para. $A$ violência só vai aumentar, e muitas das vezes, como foi dito aqui, a gente pensa que não, mas a gente acaba apagando fogo com gasolina, você quer remediar uma situação, acaba que você põe mais lenha naquela fogueira e aí aquela agressão, aquela violência, aquele fato vai ficando cada vez pior, mesmo que não seja com a mulher que eu estou convivendo... Como ele falou [menciona fala anterior de participante do grupo], "eu não quero nem mais olhar pra cara dela, a partir daquele momento ela acabou pra mim", mas ele vai ter outros relacionamentos, como já está tendo, e o que a gente não quer é que mesmo nos próximos relacionamentos venha a acontecer de novo, novos tipos de agressões, e aí é quando a gente tá tentando interferir nesse sentido. Aqui com certeza nós não queremos mudaro pensamento de vocês, nós não queremos fazer com que vocês sejam outras pessoas, nós simplesmente queremos que vocês possam compreender e refletir diante dessa situação toda que tá acontecendo. (...) Então, independente do que tenha sido, acontecido, ou culpado ou não, nós vamos estar trazendo pra vocês isso, para que possam refletir sobre meus atos, onde eu posso mudar? Porque é muito fácil apontar o erro do outro, o difícil é falar que eu errei, porque eu estou sempre certo. (...) Então nós temos que ter respeito aos colegas que estão aqui, porque a partir de hoje nós seremos, eu vou dizer aqui, uma família. Vocês vão entender isso no final do encontro, nós já tivemos encontros que no final eles pediram pra que tivessem mais, tivemos festinha, trouxeram salgadinho, fizemos uma despedida,
7| Essa resistência também

foi observada por outras pesquisadoras em seus contextos de pesquisa - entre outras, Comes (2010), Moraes e Ribeiro (2012) e Oliveira (2016). 
artigo|PauloVictorLeiteLopes|Formas degovernoecomplementaridadeentreaadministraçãoestatal

porque foi muito legal. Eles chegaram aqui com o mesmo pensamento de vocês, com a mesma indignação que ele ali, de "eu não sou culpado", mas aqui nós não estamos culpando ninguém. No final do encontro eles saíram daqui agradecidos porque eles tiveram uma visão, um olhar diferente. É a mesma coisa que eu pego [pegando uma folha A4 e mostrando aos homens] essa folha de papel e eu faço um ponto aqui [faz no meio da folha], aí eu pergunto pra vocês: o que vocês estão vendo aqui? Vocês vão falar: "esse ponto que a senhora colocou aqui". Não, não tem só esse ponto aqui na folha de papel! Ela tem quatro lados, ela é comprida e ela tem outras coisas aqui, vocês só conseguem enxergar esse ponto que eu fiz, mas essa folha tem muito mais coisas pra gente enxergar. Agora, a nossa vida é assim, às vezes a gente só enxerga aquilo ali que eu quero, mas ela tem um monte de coisas em volta que nós temos que ver; e é o que nós vamos estar mostrando pra vocês, esses quatro lados dessa folha aqui, eu quero mostrar pra vocês, e aí vocês vão sair satisfeitos daqui.".

No trecho trazido acima, mas também em diferentes momentos da condução dos grupos, Débora, Joca e Pedro ressaltavam que os grupos não são "para punir", mas para "ajudar" e "orientar", sem querer, no entanto, "mudar o pensamento" dos homens ou desejar que se tornem "outras pessoas". Em suas auto apresentações também pareciam procurar elaborar uma imagem sobre eles (e sobre o serviço) diferente daquilo que aqueles homens poderiam esperar de uma instância estatal-administrativa-judicialmais hierárquica, distante e até hostil, logo, menos compreensiva, íntima e atenta às individualidades. Um bom exemplo são aspectos acionados por Débora para apresentar o caráter que o grupo assume: como "uma família", com "festa", "agradecimentos" e "pedidos" de mais encontros em seu encerramento, revelando não apenas uma abertura e acesso à determinada informalidade em seu cotidiano, mas também como algo que produz uma espécie de satisfação entre seus participantes, dado que as pessoas o avaliam positivamente, são gratas e até demandam por mais.

Em encontro de outro grupo, através da narrativa de um dos atendidos, é possível observar a atualização de alguns desses pontos. Fabrício, um dos atendidos, contou que tinha um "acerto" de ver a filha sempre que quisesse e que pagava a pensão, "o que ela [a mãe de sua filha] pediu", mesmo não podendo. Contudo, pouco tempo depois de selarem essa combinação, foi impedido de ver a criança. Mais do que isso, relatou que a sua ex-esposa o agrediu quando tentou buscar a sua filha. Diante da recusa, passou na casa de sua mãe e depois foi para a sua casa. Lá chegando, pouco tempo depois, sua mãe chegou avisando: "se prepara que ela foi dar parte de você". "Dar parte de mim? O que que eu fiz? Eu não fiz nada!". Depois de 15 dias chegou uma carta convocando-o para a delegacia. Lá, ao conversar com quem o atendeu, disse que não agrediu a mãe de sua filha e mostrou as marcas que ainda tinha das agressões que ela havia cometido. Em resposta, o atendente teria dito: "e por que você não veio à delegacia primeiro do que ela e deu parte?" ("Tá vendo... é o que a gente sempre fala”, disse Débora). Fabrício continuou: "Se eu for na delegacia e depois eu contar pros meus amigos, a primeira 
coisa que eles vão fazer é abrir a boca e ficar quáquáquá. Vão olhar um para cara do outro e... quáquáquá, "apanhou de mulher!" Vou ficar como, né?”. O atendente falou: "Não pode ser assim, não". Débora e Joca cortam Fabrício e ressaltam que "esse é o procedimento" [ir à delegacia e fazer o Registro de Ocorrência], pois, segundo Débora, "muitas vezes acaba que você fica prejudicado e ela não". Joca destaca que ele ainda "teve sorte", porque o cara ainda "te deu voz". E concluiu: "tem uns que chega assim e: 'meu irmão, você está preso!'”.

Deslocando-se da cena na delegacia, Fabrício comenta um pouco sobre seus comportamentos e emoções: "Vou ser honesto: Eu tenho muitos problemas nas costas, esse não é meu primeiro processo, nem nada. Eu tenho processo de agressão, não só contra a minha ex-esposa, contra um próprio colega meu". E continuou: "Pô, eu não sou assim de levar qualquer desaforo para casa. Eu não aceito levar desaforo para casa, sou ignorante... eu brinco, converso, zoo com todo mundo, sou um bom rapaz de se lidar, mas só que eu também sou de sangue quente...". Sobre a sua vida, ainda contou que passa por "várias provações, todo mundo na rua sabe que eu sou sangue quente". Conta, no entanto, que encontrou uma solução: "O que é que eu faço agora? Eu não bebo mais na rua com ninguém ("Exatamente", diz Joca no meio da narrativa dele), eu fico junto com a minha família em casa. Eu posso até gastar 10, 15, o salário todo, mas compro a minha cervejinha e bebo dentro de casa, faço um churrasquinho ("Isso mesmo, gente, bom exemplo...", comenta Débora). Se eu vou pra um bar, eu vou com a minha família, com a minha mulher, com a minha mãe, com o meu pai, com o meu cunhado, com a minha irmã... é isso aí! Junto com eles, ali eu bebo. Acabou ali, eu vou pra casa.... porque negócio de ver o sol quadrado, feito meu parceiro ali [mencionando um dos participantes do grupo que esteve preso] já viu, é muito ruim. Débora interrompe e diz: "Por isso que eu te peço que você não pode faltar mais. Você já teve aquela falta (Joca confirma: "éééé"), porque se não você vai ter que repetir como no caso dele [um participante que, por não ter concluído os encontros mínimos, acompanhava o grupo novamente]. (...). Porque o juiz fica perguntando pra gente... E se ele não cumprir com todas essas participações no grupo, ele pode ser preso. É o que eu falo para vocês. Então, não faltem mais, né, gente. Vocês não podem faltar por causa disso".

Por fim, Fabrício afirmou que no mês anterior "quase fui preso por causa da pensão". Segundo ele, estava "pagando certinho", mas que, no passado mais distante, ficou um ano sem pagar, "só de raiva" - porque não vê a filha sempre, não vai às festas etc., apesar de amá-la. (...) Débora esclarece que pensão alimentícia não é para a mãe, é para a filha. E ela continua: "Tô muito contente de você poder desabafar, contar esses seus problemas... Isso aqui é pra isso, gente ("é pra isso", confirma Joca). Não é para, como ele falou, ficar calado, ficar quieto aqui porque eu estou com muitos problemas. O nosso objetivo aqui é esse, fazer com que você possa trazer pra gente um pouco dos seus problemas pessoais pra gente poder ajudar, para a gente poder orientar, para a gente poder fazer com que vocês possam dar continuidade à vida tranquilamente. 
Porque, às vezes, um simples fato, essas mínimas violências, elas causam um dano muito grande na nossa vida".

Relacionando a narrativa de Fabrício com as suas experiências, a psicóloga revelou a violência que, segundo ela, algumas vezes comete no trânsito, concluindo: "Porque durante a minha vida eu aprendi essa questão da violência, da mesma forma todos que estão aqui. (...) Então nós podemos desconstruir isso, podemos fazer com que... peraí, eu posso resolver esse problema, mas eu não preciso xingar, humilhar e ofender. (...) Não só com o meu chefe, com os amigos do futebol, mas também com a minha família. Se as pessoas estão me humilhando, eu dei margens para que as pessoas possam fazer. Agora, eu também posso mostrar para eles que tem limites, que eu não quero mais que você brigue, me xingue ou que me chame de 171, porque não cabe a mim... Então você pode colocar limites àquela pessoa sem que você tenha que xingar, falar palavras, humilhar etc.".

$\mathrm{Na}$ interação trazida acima, Fabrício compartilha as dificuldades que enfrenta ao longo de sua vida por ser "ignorante", por não levar "desaforo pra casa", apesar de ser "um bom rapaz de se lidar". Trata-se do relato de um sujeito que, em razão de comportamentos alheios, das situações da vida, daquilo que indica como "provações" e de sua natureza individual, por ser "sangue quente", sofre. É vítima "dos outros", mas também de si, visto que há algo nele que não deseja ou controla. Na verdade, quando tem agência, quando não se vê constrangido por sua natureza "ignorante" ou pelas "provações", Fabrício não só é "gente boa", mas também é capaz de forjar soluções para as situações "complicadas" da vida - por exemplo, ir ao bar somente com a família ou apenas beber em casa. Portanto, ele faz uma elaboração de si, em ocasiões específicas, como vítima das circunstâncias.

A partir da maneira como Fabrício elabora a narrativa sobre a violência doméstica em que responde como autor, da interação mantida ao redor disso e das intervenções realizadas pelos técnicos ao longo da fala dele, é possível observar a atualização dos aspectos trazidos na citação de Débora sobre a natureza do grupo e seus encontros. Nesse sentido, retomando a ponderação já feita acerca do desejo de diluição de hierarquia na prática dos técnicos, é oportuno observar não só as ponderações realizadas por Débora e Joca, mas também a própria revelação que a primeira faz sobre violências que pratica. Não obstante, a exposição de Fabrício evidencia um estilo narrativo que se revelou característico daqueles encontros, e que, para mim, é central à emergência de uma experiência específica entre aqueles grupos: através das escutas e dos relatos desses "casos", eles conformam uma "comunidade emocional" (Jimeno, 2010).

Ao tratar da utilização da categoria "vítima" por segmentos de movimentos sociais na Colômbia, Myriam Jimeno (2010) argumenta que uma das consequências de seu uso é a emergência de "comunidades emocionais". A autora defende que a "alta expressividade" da categoria torna possível o desenvolvimento de laços entre 
uma grande variedade de sujeitos, visto que sua operacionalização é uma espécie de mediador simbólico entre uma experiência pessoal, subjetiva, e a generalização social, coadunando, através dos testemunhos pessoais que se produzem em torno dela, com a emergência de uma "versão compartilhada dos acontecimentos de violência da última década [na Colômbia]”.

Apesar dos cenários, temáticas e atores distintos, acredito que esta perspectiva constitui interessante caminho para pensar a produção dos grupos que acompanhei. Uma diferença central, no entanto, é a ausência da utilização da categoria vítima para se referirem a si mesmos nas narrativas que produzem. Isso não significa, por outro lado, que eles não recorram a esse expediente, da construção de si como tais, e de dinâmicas encadeadas ao redor disso, como a realização de uma denúncia e o exame de seus sofrimentos, como meios de elaboração de si. Reforço, portanto, que ainda que não se tratem por meio da categoria vítima, até mesmo pelos imperativos e constrangimentos existentes naquele espaço em torno da definição de vítima e do gênero (em seu duplo sentido) do sujeito que pode se arvorar com tal, o sofrimento como experiência vivida e narrativa compartilhada me aproxima das reflexões propostas pela autora-e esse ponto de contato, entre minha pesquisa e as reflexões de Jimeno (2010), é fundamental para perspectiva aqui adotada. ${ }^{8}$

É preciso destacar, contudo, que a elaboração do sofrimento pode ser relevante, mas não é o único meio que permite o surgimento de elo entre os participantes dos grupos que etnografei. Para que desabafos, lamentações, confissões e outras formas de relatos pessoais possam ocorrer, o compartilhamento de espaços que se organizem por uma lógica 'humanitária, solidária e acolhedora', não caracterizado por forte hierarquia e/ou demarcação de distância intransponível, parece ser relevante. Essa configuração, revelada como uma qualidade do grupo, é reconhecida e afirmada tanto pela equipe como pelos participantes no encerramento dos encontros, é central ao desenrolar do grupo e também ao argumento aqui desenvolvido

Nesse sentido, o fundamento desse compartilhamento de experiências e desejos, substrato para que as dicas, elogios e sugestões encontrem ouvidos e bocas atentos/ as e disponíveis, ou ainda que se avalie a experiência como positiva, também está em uma espécie de sinergia, empatia, proximidade entre os sujeitos que parece viabilizar uma interação mais próxima entre eles. A condução dos grupos a partir de uma espécie de informalidade, que pode ser pensada como produto e produtora de empatia e identificação, é feita através de um cotidiano em que a jocosidade pode se constituir como uma importante linguagem de comunicação entre os sujeitos. A presença de perguntas e dicas a respeito dos casos dos outros, as narrativas de experiências de vida particulares - independente da relação que os reúne ali - e a existência de brincadeiras e piadas, revelam a existência de algum nível de intimidade e abertura para que, a despeito dos desconhecimentos, distâncias e diferenças entre si, os sujeitos possam saber das vidas um dos outros e, ao mesmo tempo, sugerir comportamentos, atos, 
soluções, conformando certo espírito comunitário e de cuidado. Ao mesmo tempo, o reforço à ausência de distâncias, hierarquias ou fronteiras entre eles, pode ser feito quando os sujeitos se esforçam em apresentam-se iguais, compartilham experiências pessoais, de êxito ou não, mostrando-se inclusive falhos, sejam os técnicos ou os homens - como vimos com Débora acima.

O que importa notar é que, como discutido acima, há um engajamento, em especial dos técnicos, na conformação de um tipo de sociabilidade que conduz a uma compreensão e elaboração do grupo como um espaço em que as hierarquias se diluem, "onde todos são iguais". Contudo, ao mesmo tempo, é possível observar outra operação que, de modo sutil, funda-se e reforça a assimetria entre técnicos e atendidos. É por meio da reinscrição dessa diferença, produzida por meio das duas técnicas de poder aqui analisadas - "formas de aconselhamento" e "fórmulas de compromisso" (Lugones, 2012) -, que estratégias finas de controle, produção de subjetividades e sujeição são atualizadas a partir do contexto etnografado. Vejamos a seguir.

\section{SOBRE AS “FORMAS DE ACONSELHAMENTOS”}

Ao realizar a sua etnografia a partir do Tribunal Prevencional de Menores de Córdoba, Lugones (2012) identificou duas "técnicas de gestão" que conformavam a relação entre administrados e administradores durante o seu trabalho de campo: as "formas de aconselhamento" e as "fórmulas de compromisso". Sobre a primeira, as "formas de aconselhamento", a autora argumenta que elas constituem uma operação habitual das administradoras judiciais, caracterizadas por serem mais próximas da figura do "conselho" que do "assessoramento técnico", este último previsto "normativamente" como parte das suas atribuições. Em comum entre esses três atos, está a existência de alguma assimetria entre aquele que "oferta" e aquele que "recebe". Essa diferença constitui-se como um elemento central a esses gestos, dado que é preciso reconhecer essa "autoridade" e/ou "legitimidade", não necessariamente jurídico-legal, entre esses dois atores, para que tais práticas se manifestem.

De início, portanto, é oportuno destacar que esse aspecto complexifica as relações que destaquei como representativas de um esforço de diluição de hierarquias entre técnicos e atendidos. Se, por exemplo, o terreno das brincadeiras poderia fazer crer, ou estabelecer, um terreno de igualdade, a expressão continuada das "formas de aconselhamento", por outro lado, as reelaboravam em outra direção, ainda que de forma discreta, diluída e menos perceptível.

Um tema recorrente nos grupos que acompanhei refere-se às possibilidades de enfrentamento ou os caminhos e soluções para lidar com dificuldades, tensões e conflitos nos relacionamentos. O "diálogo", "a conversa" e "a comunicação" são apresentados pelos técnicos - e pelos artefatos acionados, como os vídeos e as dinâmicas utilizadas - como estratégias fundamentais à prevenção de violências 
e à realização de uma vida familiar saudável. Esse cenário, tema e abordagem, se repetiam ao longo dos encontros, acionando e veiculando, cotidianamente, "formas de aconselhamento" como os trazidos na interação a seguir:

Joca: A maioria aqui tem filhos, eu queria perguntar aqui para vocês se a maioria tem o hábito de parar, sentar, chamar os filhos, conversar... Vocês têm esse hábito? (...) Naquele outro vídeo [refere-se ao documentário "Silêncio das Inocentes", exibido em encontro anterior], que a Dra. Adriana fala que nós perdemos o hábito de fazer uma refeição juntos... Pelo mercado de trabalho, às vezes a mulher trabalha também, tanto quanto o homem, finais de semana, hoje é comum, né, quase todas as casas, tem mais de uma TV. Então, um quer ver futebol, pega o prato e vai ver futebol; outro quer ver Sílvio Santos, pega o prato e vai ver Sílvio Santos. E não tem mais aquele almoçar... ["na mesa”, em uníssono vários homens completam; "reunião", disse outro depois].

Na sequência, um homem comenta que tem três televisores em casa.

Joca reage: Ainda bem, né? O país melhorou nesse sentido, mas, em contrapartida, nós estamos, realmente, perdendo esse hábito de sentar... e ali é o momento pra conversar, falar das nossas necessidades... e hoje tá muito difícil...

Débora: E também saber o que se passa com os filhos, né?! Porque é importante você dialogar nesse momento de calma... porque, às vezes, ele também tá estudando, ou a menina, enfim, se for pequeno, se for adulto, adolescente... não tenho tempo de saber o que está acontecendo. É muito fácil você é... é... observar o comportamento do filho da seguinte forma ("Boa ideia, hein?!", comenta um dos homens). "Pai, posso ir no shopping, no show... em algum lugar?". "Ah, tudo bem. Pode!". Mas volta 10, 11, meia-noite ou no dia seguinte... e o pai não quer saber! "Por que você chega tarde? Eu falei que era pra dez horas tá aqui!" [entonação que busca simular briga]. Não tenho diálogo pra saber o que está acontecendo... "você foi para o shopping? Com quem você foi? Quem são seus amigos?". Não que queira que apresente [os amigos do filho], mas mostrar o amigo-pai, o interesse-pai, e não com agressividade, querer saber... Muitas das vezes os próprios filhos estão usando drogas e os pais não sabem. E a única coisa que faz é agredi-lo fisicamente ou verbalmente. (...) Muitas das vezes pode ter acontecido com a gente na infância. Na nossa fase de adolescente, o pai e a mãe não tiveram a oportunidade de sentar e conversar pra saber o que estava acontecendo com a gente. E a gente fica pensando: meu pai não fez isso comigo por que que eu vou fazer com meu filho?

Em outro grupo, enquanto realizavam uma das dinâmicas disparadoras, a emergência de algumas narrativas recentes sobre violências praticadas dava a oportunidade para que os técnicos os lembrassem de alguns dos mecanismos 
jurídico-legais que os governam, em especial a suspensão condicional do processo e as medidas protetivas ${ }^{9}$. Ao mesmo tempo, indicavam os "riscos" que eles corriam caso se envolvessem em novos conflitos ou outros processos. Como alguns desses relatos começavam com expressões como "há pouco tempo", "no mês passado", "outro dia", logo que a violência era narrada havia o questionamento do ato e consequente "aconselhamento" para que, nos próximos anos, "fique sapatinho".

Valter iniciou a sua narrativa contando que, naquela semana, "quase" tinha se envolvido em uma briga no trabalho. Disse que é motorista e que "foi fechado" quando saia com o caminhão do estacionamento: "Já tava irritado com o calor que fez na semana toda e comecei a xingar ele. Aí ele foi e revidou. Nisso que ele revidou, eu falei: desce do carro e vamos resolver que nem homem. Aí começou aquela discussão de troca de insultos. Aí eu pensei: quer saber, isso não vai dar em nada! Peguei e entrei com o caminhão, fiz o contorno e fui embora fazer as minhas entregas".

Após o relato, Joca se adianta e diz "A melhor coisa que você fez...". Débora prossegue: “Exatamente! ${ }^{10}$ Até mesmo porque você tem que entender aquilo que a gente fala aqui: quem tem a suspensão condicional do processo, se envolver em qualquer discussão, como no caso do risco que ele correu..." A psicóloga é interrompida por Humberto que pergunta: “Agrava a situação?”. Após a confirmação de Débora, ele faz nova pergunta: "Por que o cara não é mais primário?".

Joca, então, inicia a sua explicitação das regras que os regulam administrativamente definindo o que significa a suspensão condicional do processo: "Todos vocês que estão aqui sob a suspensão condicional não foram condenados a nada. Portanto, todo mundo é primário, entendeu? Mas vocês estão sob a suspensão condicional. Se amanhã, eu canso de explicar isso, até mesmo uma briguinha dessa de bar mesmo, de futebol, se sair uma briga, uma confusão, que der polícia e for feito o registro, quando bater no ]ECrim [Juizado Especial Criminal], não vai para a violência doméstica, mas vai pro ]ECrim, quando eles levantarem e verem que você está sob a suspensão condicional do processo, o juiz pode muito bem cancelar essa suspensão e prender, entendeu? Porque durante esses dois anos que vocês têm que assinar lá no cartório, vocês têm que ter uma vida bem quietinha. Eu até aviso a quem gosta de tomar umas cervejinhas, compra e leva pra beber em casa... que é para não ficar no bar que sempre tem um papo ou outro, que pode surgir uma confusão... Compra cervejinha no mercado e bebe em casa, tranquilo... (Débora, interrompe Joca e diz: "Pelo menos por esse tempo, né?”). Ele retoma: “Não é necessário deixar de frequentar o bar, não, mas tem que tomar muito cuidado. Vamos supor o caso dele ali [refere-se a Cláudio, que contou pouco antes sobre essa situação]: jogou a garrafa no rapaz! Se tá certo ou errado, é outra história (Débora fala ao mesmo tempo: "Errado está!"), mas acerta o rosto do rapaz, certamente, certamente, será feito o registro de ocorrência! Iria perder a suspensão condicional do processo, entendeu? Tem que se pensar muito..." Após Cláudio dizer que "na hora não pensa", Joca conclui: "O problema é esse!"

9|A prescrição de comportamentos e interditos específicos que, quando descumpridos, podem acarretar privação de liberdade, é o elo entre as duas medidas nessas falas elaboradas pelos técnicos.

10| A narrativa de Valter e as reações de Joca e Débora apontam a uma modalidade específica de gestão no interior não do SPH: a bonificação. Trato a seguir dessa expressão e de sua relação com a discussão aqui desenvolvida. 
Em suas reflexões sobre as "formas de aconselhamento", Lugones (2012) defende que elas oscilam e se articulam entre a admoestação e o aviso, a advertência e a sugestão - como pode ser observado a partir da maneira como Débora e Joca apresentam as hipotéticas consequências familiares e jurídicas dos comportamentos adotados pelos homens (ou a eles sugeridos) nos relatos trazidos acima. Além dessas características, a autora argumenta que é necessária a existência de uma relação saber-poder a autorizar, fundamentar e legitimar o reconhecimento dos/as administradores/as como aconselhadores/as, ainda que, na operacionalização cotidiana, seja a "boa intenção" que dê a forma ao gesto. Há também um léxico comum entre o comportamento aconselhado e a moralidade compartilhada com o sujeito para quem ele se destina. Isto é, uma correspondência entre o conteúdo da recomendação e as crenças/concepções de quem as recebe, que opera para conferir autoridade/legitimidade àquela interação - é possível observar isso, por exemplo, na interação em que os próprios homens completam a fala de Joca acerca da importância de compartilhar refeições em família.

Nessa direção, é oportuno destacar que pude observar seguidas vezes a apresentação dos técnicos, sobretudo de Débora e João Carlos, a partir dos seus campos de formação: Psicologia e Direito. Muitas vezes eram chamados pelo outro, e às vezes eles mesmos se intitulavam, como doutores - Doutora Débora e Doutor ]oão Carlos, passando a também serem assim chamados pela maior parte dos homens. Era comum, inclusive, que um introduzisse a intervenção do outro com essa justificativa: "a Doutora Débora pode falar melhor, porque é um tema da psicologia" ou "vou deixar com o Dr. João Carlos que pode te orientar melhor, pois ele é advogado". Os temas tratados na maior parte dos encontros, talvez pelos arranjos produzidos no interior de um juizado de violência doméstica, articulados na intersecção entre emoções, moral e direito, configuravam-se de maneira porosa e possibilitavam a transferência daquela autoridade referenciada aos seus campos de formação e a temas correlatos a esses a uma ampla gama de questões e temáticas muito variadas. Havia, portanto, certa representação da autoridade que passava pelo lugar que ocupavam, 'representantes da justiça', mas que também, ao longo do grupo, articulava-se contextualmente aos temas em questão, aos seus campos de formação e às suas habilidades retóricas.

Embora formações acadêmicas fossem enfatizadas como forma de produção de legitimidade, isso não impedia que tratassem de elementos que seriam referentes a outros campos de saberes e práticas, revelando uma espécie de plasticidade das temáticas alvo do "aconselhamento". Se, em princípio, o reconhecimento emergia a partir do campo de formação e da temática em questão, isto é, advogado e psicóloga eram autorizados a tratar de assuntos relativos à violência doméstica e seus correlatos mais diretos, no decorrer dos encontros era possível reconhecer a incidência sobre uma ampla gama de temas e espaços de administração e/ou aconselhamento. Além das referências à diversão e consumo de álcool, trazidas anteriormente, também pude acompanhar, da parte de técnicos, críticas a determinados estilos musicais considerados 
de qualidade inferior, como forró, funk e pagode, e também recomendações sobre a importância e o valor da leitura.

Fazendo referência a um caso de violência trazido em um vídeo exibido naquele mesmo encontro, Joca menciona que o sujeito "não aceitou o sucesso da esposa". Tadeu, a partir da afirmação sobre o sucesso da vítima, argumenta que ela foi mais inteligente que o agressor, mas que os dois, homens e mulheres, são igualmente inteligentes. Joca concorda destacando que todos possuem a mesma capacidade, mas uns desenvolvem mais e outros menos. Joca cita uma música de Raul Seixas em que ele fala que o ser humano usa $10 \%$ de sua inteligência e emenda: "Mas agora você vê, e aqui não vai nenhuma crítica pessoal, até porque eu estou inserido nesse contexto, tem muitos de nós que, quem hoje não assiste aquele programa "corta pra mim, Percival"? [Referência ao programa Cidade Alerta, exibido pela Rede Record de Televisão, e ao bordão do seu apresentador, o jornalista Marcelo Rezende]. Aquele cara nojento fala... Cara, se você botar a tua televisão no canal dois, você vai ver a programação da TVE, TV Educativa. Lá não vai ter ninguém falando "corta pra mim". [Risos do grupo]. Aí você vai ficar vendo aquilo, você vai ficar bitolado... Como até pouco tempo atrás era aquele "escracha!" [referência ao programa Balanço Ceral, exibido pela mesma emissora no Rio de ]aneiro, e ao bordão do seu apresentador, Wagner Montes]. Entendeu? Então, se você procurar desenvolver o teu lado intelectual, não é a escolaridade; escolaridade é diferente do cara desenvolver a questão intelectual dele. Pô, bota lá na TV Brasil, no canal 2, que você vai desenvolver... Você até pode ver o "corta pra mim", mas não veja tudo, veja uma parte [Risos]. Entendeu? Quer ver? Quem daqui ouve "A voz do Brasil"? (Tadeu diz: "Não, realmente, eu não tenho ouvido....) Cara, aquilo ali rege a nossa vida! ("Eu não tenho ouvido", diz outro) Ninguém ouve aquilo... ("Eu tô sem rádio", justifica Tadeu) Aquilo ali você sabe notícias do Planalto, do que a dona Dilma tá lá assinando neste momento... E o cara quer saber do Flamengo! Eu também quero saber do Flamengo, que eu sou flamenguista, mas eu quero saber como é que estão as outras situações.".

Ante aos comentários e recomendações de João Carlos, Tadeu se justifica e reage: "Não, uma coisa que, realmente, antes de sair do trabalho eu vejo, aquela "última sessão" [série de desenhos infantis exibidos no início da amanhã no canal SBT], eu vejo os desenhos, depois começa o... o... telecurso! Aí aquilo ali, com certeza, eu não vejo ele todo, porque não dá tempo de ver ele todo, mas eu vejo uma boa parte dele... Ali eu tô exercitando a minha mente!".

A partir da interação acima, é possível identificar outra característica das formas de aconselhamento: a existência de determinada confluência moral entre aconselhador e aconselhado, isto é, a existência de "crenças compartilhadas" entre ambos (Lugones, 2012: 187). Aos aconselhamentos de consumo de programas televisivos "educativos" e à necessidade de "desenvolver a inteligência", Tadeu reage, não apenas reconhecendo e justificando a sua falha ("Realmente, eu não tenho ouvido"; e "Eu tô sem rádio"), mas também apresentando uma opção, um comportamento positivo similar ao que 
João Carlos sugeria, portanto, reconhecendo a legitimidade e o valor da sugestão (ele assistia o "telecurso").

Ainda seguindo a proposição de Lugones, as "formas de aconselhamento" transitam entre diferentes questões e amplificavam seu campo de atuação não apenas pela porosidade de temáticas que se articulam na intersecção, como dito anteriormente, de emoções, moral e direito, mas também em razão de duas características centrais que possui: a existência das "formas de aconselhamento" como expressão do "poder tutelar", conforme proposto por Pacheco de Oliveira (1988) e Souza Lima (1995), e, por outro lado, a sua eficácia como técnicas de "menorização", como discutido por Vianna (2002).

Os mecanismos tutelares articulam-se a partir e através de uma assimetria fundamental no que se refere a direitos, mas, ao mesmo tempo, operam por meio de uma série de atuações que acionam diferentes técnicas de regulação de comportamentos e hierarquias. A tutela, portanto, está relacionada a esse duplo movimento: ela depende que determinados sujeitos reconheçam a sua subordinação, e, ao mesmo tempo, que outros sujeitos assumam o dever/responsabilidade de conduzilos e, desse modo, garantam (ou produzam) a eficácia da gestão dessa população.

Nos encontros entre o Juizado e as casas, ou ainda entre o Estado e a família, a regulação de tais comportamentos e a condução dos sujeitos assume, a partir das formulações de Vianna (2002) e Lugones (2012), contornos daquilo que as autoras chamam de "menorização", uma das formas de atualização "tutela". Recorrendo a exemplaridade da figura do "menor", e destacando que a "menoridade" é uma relação de dominação, Vianna (2002: 7) argumenta que "ser menor" é "encontrar-se em posição de autonomia parcial, por quaisquer motivos que sejam considerados operantes em um dado momento e em uma dada configuração social". Nessa direção, ampliando a noção além do espectro etário, afirma que o "menor", sob essa perspectiva analítica, é alguém que se encontra em "um conjunto de relações de autoridade em posição subordinada, ou seja, não apenas colocado em meio a relações de interdependência, mas, sobretudo, de assimetria".

A partir de tais considerações, é importante destacar esse duplo aspecto que conforma não só a emergência das "formas de aconselhamentos", mas a ampla e diversificada variedade de temas e questões que lhes são objeto: 1) o reconhecimento dos administradores, daqueles que conduzem ou que são os tutores, de sua superioridade com relação aos seus administrados/tutelados, nesse caso, não apenas nos temas relativos à violência doméstica, mas em torno daquilo que é possível pensar como construção da pessoa, daí a riqueza da relação com a "menorização"; e 2) de maneira articulada a isso, o dever moral e administrativo dos administradores em "assistir (acompanhando, auxiliando e corrigindo) a conduta do tutelado, de modo que o comportamento deste seja julgado adequado" (Pacheco de Oliveira, 1988: 224). 


\section{SOBRE BONIFICAÇÃO E FÓRMULA DE COMPROMISSO}

Outra forma de atualização daquilo que Souza Lima (1995) chamou de "poder tutelar" é produzida por uma técnica de poder que nomeei como "bonificação" - esta se expressa através de elogios, enaltecimentos e na chancela de gestos considerados positivos/exemplares. Como as "formas de aconselhamento", por meio dessa modalidade também é possível identificar aspectos relacionados ao estabelecimento e ao reconhecimento da autoridade de uns, a subordinação de outros, e, ao mesmo tempo, observar o investimento dos primeiros em assistir a conduta dos segundos.

Ao longo desse texto, evidenciei o desejo dos técnicos de incidirem, a partir de seus valores, nas condutas dos homens. Em diferentes momentos, como na referência à atitude de Fabrício "para evitar confusão no bar", ou quando Valter se acalmou após ser "fechado" no trânsito, diante de um comportamento considerado bom ou correto, são direcionados elogios, produzindo determinado reconhecimento positivo sobre o modo como o sujeito atua, portanto, sobre aquilo que ele é. De outra maneira, em situações opostas, críticas ou questionamentos tinham como finalidade pôr em xeque algumas atitudes, revelando aquilo que é considerado (i) legítimo. Com isto, chamo atenção ao fato de que a orientação de conduta pelos técnicos nem sempre se dá sob a forma de um aconselhamento direto, mas também por outras estratégias e técnicas não menos eficazes.

Ainda a partir da formulação das "bonificações", é possível observar o investimento dos técnicos em direcionar as condutas, emoções e posturas consideradas razoáveis ou mais 'seguras' - não apenas para o sujeito que produz a narrativa, mas, considerando a presença dos demais ouvintes nas cenas, de maneira extensiva a todos. Um exemplo dessa atualização pode ser observado a partir da relação que se estabelece entre o testemunho de Vanderlei e as intervenções de Débora e João Carlos na interação a seguir. Os comportamentos não são tratados a partir das noções de "perigo", "risco" ou "segurança", como apresentados anteriormente, mas em torno das "vantagens", "ganhos", "melhorias". É o caráter de exemplaridade que o comportamento ganha que desejo destacar aqui:

\footnotetext{
Vanderlei: Eu tenho uma coisa pra falar, eu acho que a minha história de vida é bem bacana, desde que ocorreu essa tempestade toda comigo. Então a minha história de vida hoje tá sendo bem bacana, porque, assim, tem um ditado que a gente só fecha a porta quando é assaltado, né? (...) Então, depois que a gente voltou, a nossa relação tá bem bacana mesmo, entendeu? Tanto da parte dela como da minha parte também. Ela tá me respeitando bastante. Eu também tô respeitando ela. A gente tá contribuindo, junto, com o nosso filho. $\mathrm{O}$ diálogo da gente mudou bastante... É como se a gente tivesse vivendo uma nova lua de mel, tá entendendo?
} 
Débora: Olha a importância do que você tá falando: "ela tá me respeitando e eu estou respeitando ela!". Isso é fundamental em um relacionamento...

Vanderlei: (...) Assim, agora, hoje, praticamente a minha vida tá superando cada dia mais. Quer dizer, a gente tá vivendo uma história de vida, praticamente. A gente voltou, nosso filho é uma, tem outra autoestima, né, dele ver a gente bem... Ele ri, ele brinca com a gente, a gente passeia junto, a gente não fica mais aquela coisa de ficar um esperando pelo outro, não?! Chega o fim de semana, ela trabalha e eu também trabalho, vamos passear? Vamos! Nós pegamos nosso filho...

Débora: Olha a outra importância do que ele disse: a partir do momento que ele ficou bem com a mulher, os filhos também ficaram bem ("Reflete nas crianças", comenta outro atendido) reflete nas crianças... Por mais que estejam morando juntos ou não, "ah, mas eu não estou mais morando com ela". Tudo bem, não é o caso deles, eles estão juntos, mas a importância de se dar bem com a mãe do meu filho faz com que ele possa se sentir bem: "Ah, tudo bem, meu pai e minha mãe não tão morando juntos, mas eles estão bem". Isso é importante para aquela criança.

Vanderlei: Então, como a senhora falou, meu filho, ele sofreu muito. Não só ele, como eu, ela também..

Joca: Mas a criança sente muito mais.

Vanderlei: Sente muito mais, não tem a presença do pai, da mãe muito pouco, porque também, em casa, ele sempre ficou mais com a avó dele, do que comigo ou com ela. Ele não queria mais ficar com ela, porque ela é um pouquinho mais agressiva com ele, COM ELE [enfatizou Vanderlei]. Porque ela quer educar de uma forma, sabe, muito rígida, até eu concordo, porque não pode deixar é...

Débora: É, tem que ter limites (Vanderlei repete: “Tem que ter limites"). Não pode deixar, nem apertar muito e nem liberar muito.

Vanderlei: Eu sou mais aquele paizão bobo, né, que brinco, deixo, só grito... É mesmo. Às vezes quando não é o pai, é a mãe, que gosta de ser mais agressivo. Eu sou mais aquele bobão de só falar, gritar e deixar pra lá. Ela não, ela já corrige... Então, aí o garoto sofria muito, ficou magrinho, sabe, abatido... Depois que a gente voltou, poxa, tem que ver... Uma bênção!

Ainda que tenha apresentado a "bonificação" através dos elementos que a aproximam ou vinculam às "formas de aconselhamento", é interessante pensá-la a partir de algumas configurações de outra "técnica de gestão" identificada por Lugones (2012): a "fórmula de compromisso". Em sua conceituação a respeito da manifestação dessa técnica, a autora revela que ela emerge em um "panorama normativo cambiante", em que a possibilidade de perda da guarda do "menor" se constitui como uma "forte presença", conduzindo, desse modo, a assunção de obrigações e compromissos, da parte das administradas, visando não só a manutenção da guarda "do menor", mas, ao mesmo tempo, o seu deslocamento da posição "menorizada". Apesar da nomeação 
de "compromisso", a autora destaca que isso não significava que, após firmados, essas mulheres se engajariam em seu cumprimento, dado que a sua realização se encontrava na própria enunciação (e no seguinte registro nos "autos" do processo). Como afirma, "no se trataba de acuerdos ni de convenios sino de fórmulas a partir de las cuales se extendía virtualmente la acción y presencia estatal" (Lugones, 2012: 194). Ao retratar os elementos que compõem a técnica, Lugones (2012: 198) argumenta:

\footnotetext{
Estas fórmulas llevan a (re)considerar como compatibles dos dominios tenidos como antitéticos: el de la fe y el del cálculo. Habría un cálculo presumidamente racional sobre las medidas que se tomaban, de lo que se consideraba admisible o inadmisible, al mismo tiempo que la técnica de formular compromisos introducía la fe, la creencia en la palabra empeñada, conformando una incumbencia mixta, sin por ello alejarse del "derecho" que, desde sus orígenes romanos tendría como "lo constitutivo no el hacer, sino más bien el pronunciar" (Benveniste apud Supiot, 2007: 83). Las fórmulas de compromiso se cifraban en un "dar crédito" de la administración a la palabra empeñada por los administrados y su correlato, asumirse "acreedor" del cumplimiento de alguna "obligación".
}

A partir de tais discussões, é possível compreender a bonificação como uma operação que, ainda que guarde as características das formas de aconselhamento, também reúne algumas propriedades das "fórmulas de compromisso". Entre "a fé e o cálculo", observa-se a constituição mútua entre administrados e administradores (ou entre atendidos e técnicos), possibilitada pelo acompanhamento das condutas daqueles sujeitos. Isto porque as narrativas são elaboradas considerando uma certa plausibilidade acerca do que está sendo dito, isto é, os homens fazem uma avaliação sobre conteúdo e a forma do que será compartilhado, procurando contemplar critérios específicos de validação, reconhecimento e correção moral. Por outro lado, os ouvintes (outros atendidos e administradores) depositam, em algum grau, a crença naquela narrativa trazida no grupo. Apenas a partir da combinação desses fatores, na interação entre aqueles atores, que as bonificações podem emergir em sua concretude.

As situações e falas elaboradas nas narrativas dos administrados e a consequente bonificação operada pelos administradores, portanto, consistem em uma espécie de meio-termo, ou um terceiro, entre os dois formatos elaborados por Lugones (2012). Para melhor compreender esse dispositivo, é preciso destacar que a emergência dessa técnica deve ser tomada como fundamentalmente relacionada ao lugar/momento que aquele serviço ocupa/desempenha em termos de trajetória administrativa em meu campo - sobretudo se comparado ao trabalho de Lugones (2012) no Tribunal cordobés.

O SPH se caracteriza por uma atuação continuada junto aos homens, durante um período de tempo previamente delimitado e reconhecido por todos (oito encontros mais um de avaliação), além de ser executado, de certa maneira, após o trâmite do 
processo judicial. Assim, por exemplo, se comparado com a etnografia de Lugones, o espectro da "espetacularização da soberania" (Vianna, 2002), expresso naquele contexto através da possibilidade de cassação da guarda do "menor", é (quase) nulo. Nesse sentido, é oportuno refletirmos sobre as (condições e) possibilidades de emergência desses relatos pessoais, que se referem à exemplaridade das suas próprias ações, mas que também revelam outros atores e êxitos nas interações mantidas na e através daquela instância administrativa.

\section{NOTAS FINAIS}

Em suas reflexões sobre a gestão da menoridade a partir de processos judiciais anteriores e posteriores à implantação do Estatuto da Criança e do Adolescente (ECA), Vianna (2002) defende que é na dinâmica da "complementaridade" entre o juizado e as casas que a administração estatal se organiza. Contrariamente a Donzelot em "A Polícia das Famílias" (1986), Vianna (2002; 2003), a partir de sua pesquisa acerca da gestão da infância através dos processos de guarda, observará que esta administração não se produz em torno de "uma ação de vigilância ou de controle estrito", "ou seja, não se trata simplesmente de uma ação em que práticas civilizadoras e policialescas do aparato administrativo se fazem sentir sobre as famílias ou configurações domésticas" (2003: 295), mas, na verdade, as relações de dominação e autoridade entre profissionais e não-profissionais se articulariam de maneira mais fina, apontando para um cenário de maior complexidade nas relações estabelecidas e complementariedade entre os sujeitos, práticas e discursos envolvidos. Tais características, segundo a autora, tornam essa gestão "uma forma de dominação que se faz tão mais eficaz na medida em que opera não a partir do antagonismo entre o aparato administrativo e as unidades domésticas, mas combinando-os em uma relação assimétrica" (2003: 296).

Esses movimentos, segundo a autora, centram-se "na busca por soluções administrativas que garantam a autoridade da própria administração através não do controle, fiscalização ou repressão das relações que compõem as unidades domésticas, mas de variadas formas de negociação, conciliação e reforço dessas mesmas relações" (2002: 28), o que evidenciaria estratégias diferentes entre o Estado francês e o brasileiro na gestão de "menoridades". A partir da leitura e análise desses processos de guarda, Vianna (2002) examina a existência de uma série de ações que escapam a 'simples' avaliação do ajuste ou não às normas estabelecidas, sintetizadas em torno da consideração das condições atuais de vida do "menor" e daquele que seria o "melhor interesse"/“melhor destino", em favor de uma série de outras avaliações de "riscos" e intervenções de mediação em busca "pelo acerto mais favorável por todos os envolvidos, com demandas de diferentes níveis sendo, ou não, atendidas" (2003: 289) ${ }^{11}$. E conclui Vianna (2003: 298):

11 | A respeito das variáveis em questão, Vianna (2003: 289) sentencia: "Está em jogo, portanto, o confronto entre representações acerca do "melhor destino" para aquele que é objeto da tramitação do pedido de guarda, do que cada envolvido tem a oferecer, do que pode ser tolerado ou não nas relações entre responsáveis e menores e, de modo mais sutil, das possibilidades de comunicação e empatia moral entre demandantes e profissionais envolvidos". Ao que se refere às formas de administração de violência doméstica contra a mulher no Brasil, reflexões interessantes foram desenvolvidas nessa direção ao longos das últimas décadas - consultar, entre outras, Muniz (1996), Debert; Beraldo de Oliveira (2007), Bragagnolo et al (2015) 
Nesse sentido, o que tais profissionais criam e rotinizam são possibilidades de gestão, possibilidades de controle de populações que precisam ser pacificadas, impedidas de se transformarem no seu fantasma mais assustador: crianças malformadas, crianças que alimentem as imagens da sociedade como confronto aberto, como guerra.

Mais do que repressão, no sentido de impedir que algo se realize, porém, o que está em jogo nessa ação é a capacidade de fazer existir a ordem, enunciando-a através das "soluções possíveis" que o saber técnico, transformado também em instrumental soberano, cria: diagnosticar e, ao diagnosticar, conduzir a decisão legal, valendo-se do fundamento de soberania.

Sob tal perspectiva12, é possível ler essas técnicas, a "bonificação", a "fórmula de compromisso" e as "formas de aconselhamento", como reveladoras dessa outra apreensão da relação entre administração e casa (ou Estado e família), centrada não no conflito ou na tensão, mas na reconciliação, em uma espécie de acordo entre as partes. Ainda seguindo Vianna (2002), tal reconciliação pode ser pensada não somente entre

$\mathbf{1 2} \mid$ A respeito das reflexões de Vianna (2002) e de sua apropriação para a identificação das "formas de aconselhamento" e das "fórmulas de compromisso", também consultar Lugones (2012: 199) esses dois atores, mas, ao mesmo tempo, entre o Estado e a sua "promessa", isto é, com o conjunto de discursos, experiências e práticas que anunciam e justificam o seu dever ser - nesse caso "o enfrentamento da violência doméstica e familiar conta a mulher".

Um efeito das situações de relato-bonificação é, portanto, a dupla manifestação da eficácia dessa administração estatal: ela anuncia-se eficaz pela assunção de um compromisso, através da promessa de incorporação de determinados comportamentos nas práticas dos sujeitos, e, ao mesmo tempo, por tais "mudanças" ou ações se constituírem a partir de condutas longa e constantemente "aconselhadas" nos diferentes encontros. Ainda por meio dessas narrativas marcadas pela bonificação, é possível conduzir a novas "formas de aconselhamento" e ao agenciamento de outros "compromissos" reconhecidos e instituídos pela exemplaridade de um afim, ou seja, de outro participante do grupo e pela chancela dos técnicos.

Partindo das considerações expostas acima, é possível reconhecer em tais operações um agenciamento importante não só para a eficácia da administração estatal e da própria autorização/legitimidade daquele espaço, seus atores e técnicas na condução ou administração daqueles sujeitos, mas na garantia da legitimidade das formas de ser, existir e se comportar trazidas nos relatos bonificados. Esse aspecto é fundamental não apenas para os arranjos que se produzem em torno do Estado, mas para a consolidação e força de um modelo de atuação centrado, como destacou Vianna (2002), na coextensividade e complementariedade entre essa administração e seus administrados, em seu trabalho de produção de sujeitos e de sujeição.

Ao observar a fixação dessas narrativas em torno do estabelecimento de compromissos e da assunção de novos comportamentos e formas de manter relações pessoais, é oportuno retomar os argumentos de Vianna (2002) a respeito da atuação das assistentes sociais na condução de processos judiciais, e o modo como modelavam 
as suas avaliações e intervenções em torno do reconhecimento daquilo que seria "o possível" para aqueles sujeitos e para as suas unidades domésticas - um trabalho assentado em "compor soluções, costurar rupturas e diminuir conflitos" (2003: 299). A partir do exame dessas operações, a autora ressalta que uma análise sobre os modos como os casos eram geridos, revela que "os arranjos, conciliações e acordos promovidos" eram definidos "a partir de sua preocupação em obter eficácia na gestão de inferiores - as unidades domésticas possíveis em lugar das famílias modelares" (2002: 65).

O que se revelaria tomando essa perspectiva de análise, é a elaboração de uma gestão do possível no interior da violência doméstica. Sem dispor dos mecanismos de controle ou fiscalização sobre esses sujeitos, seus comportamentos ou atitudes, mas tendo em seu horizonte de obrigações a garantia da integridade às mulheres e, ao mesmo tempo, o dever de controlar as situações de conflito, seja em sua forma punitiva ou preventiva, o Estado deve promover e dispor de métodos de produção e aferição de sua eficácia em torno de tais questões. Sob os limites de uma administração conduzida em torno da escassez de recursos e possibilidades de ação, uma das estratégias acionadas é a identificação e produção de vínculos de parceria com os sujeitos, de modo que eles possam se tornar aliados ou cogestores dessa administração no interior de determinadas relações, conduzindo, portanto, à operação de uma lógica de complementariedade e coextensividade entre o Estado e seus administrados. No entanto, ao mesmo tempo em que se estabelecem tais relações, essa mesma administração interage e produz esses sujeitos em torno das suas insuficiências e inabilidades em lidar com as questões em que ela, nesse processo, os converte em partícipes da gestão.

A atuação que aqui emerge desse arranjo, portanto, não se dá em torno da clássica leitura que observa a ação estatal sobre os sujeitos, procurando disciplinar e conformar as suas atitudes em torno daquilo que reivindica como o ideal, mas arranjos tácitos em que o que se postula é o ordenamento possível aos sujeitos e ao Estado, em que o que se coloca como horizonte não é a obediência, a incorporação de modelos ideais de família ou relações afetivas, mas, na verdade, que aqueles sujeitos, e suas relações, não deem mais problemas. ${ }^{13}$

Nesse sentido, uma característica presente em outros encontros, mas que adquire tonalidades mais fortes no "encontro de encerramento", refere-se à compreensão das "formas de aconselhamento", a "bonificação" e as "fórmulas de compromisso" como "atos de fala" (Austin, 1962), isto é, a sua operacionalização não como enunciados que se encerram em si mesmos, mas que, na verdade, produzem coisas, relações e sujeitos. O último encontro, como culminância dessas técnicas de gestão que tratei acima, constitui-se como uma espécie de ritual da "mudança”/"reforma de si", onde, através da assunção (e retomada) dos compromissos, da revelação de novas habilidades ou de comportamentos apropriados, produz-se, na verdade, sujeitos morais qualificados, exemplares, reconstituídos a partir de outras perspectivas a respeito das suas vidas e relações. É oportuno pontuar que esse encontro também é estratégico pois é nele que as partes, de forma conclusiva,

13 Acompanho as reflexões de Vianna (2002: 240) que, ao tratar da gestão das menoridades através de processos de guarda, conclui: "O que a pragmática administrativa produz, nesse sentido, pode ser melhor traduzido como a busca por certos compromissos morais que traduzam e permitam a legitimidade do acordo tutelar - a passagem da guarda - mas que, ao mesmo tempo, saiba limitar a cobrança por esses mesmos compromissos. Enfim, que se construa o tolerável, o possível, não como realização de direitos idealizados ou de modelos ideológicos de família, mas como expediente administrativo capaz de evitar o pior.". 
estabelecem a "narrativa oficial" acerca do grupos e seus encontros, além de expressarem e sistematizarem as suas narrativas particulares, mas também comuns, em torno de toda a experiência - a violência denunciada, seus deslocamentos através e pelo Sistema de Segurança e Justiça, e, por fim, a própria experiência dos grupos.

O que parece estar em jogo é a demonstração de determinadas habilidades, mesmo que virtuais, de administrar um leque variado de questões relativas às suas relações afetivas e familiares. As três técnicas aqui analisadas constituem uma linguagem que permite dar forma a essa operação, a esse arranjo elaborado entre administrados e administradores. A performance do sujeito reformado, isto é, que domine com relativa competência os discursos e práticas pedagogicamente repetidas ao longo dos encontros, ainda que não "se responsabilize" ou "assuma" a violência nesse sentido, o que seria um dos objetivos centrais do $\mathrm{SPH}$, parece ser o elemento central aos modos de subjetivação que emergem desses encontros, mas, além disso, reificam as imagens de controle, eficácia e poder da administração estatal. Esses aspectos, portanto, nos permitem concluir que essas técnicas de gestão são eficazes não apenas por (re) produzir formas de subjetivação e sujeição dos diretamente envolvidos, mas também podem ser revelar eficazes na manutenção cotidiana da crença (e do desejo) de Estado.

Paulo Victor Leite Lopes é Mestre e Doutor em Antropologia Social (UFRJ), Professor Adjunto do Departamento de Antropologia e do Programa de Pós-Graduação em Antropologia Social da Universidade Federal do Rio Grande do Norte (UFRN), Natal, RN, Brasil.

CONTRIBUIÇÃO DE AUTORIA: Não se aplica

FINANCIAMENTO: Além de recursos do PPGAS/UFR] para a realização do trabaIho de campo, a pesquisa também contou com financiamento da Coordenação de Aperfeiçoamento de Pessoal de Nível Superior (CAPES) e da Fundação de Amparo à Pesquisa do Estado do Rio de Janeiro (FAPERJ) por meio dos seus programas de bolsas.

\section{REFERÊNCIAS BIBLIOGRÁFICAS}

AUSTIN, John Langshaw. 1962. How do things with words. Oxford, Oxford University Press.

BEIRAS, Adriano; NASCIMENTO, Marcos; INCROCCI, Caio. 2019. Programas de atenção a homens autores de violência contra as mulheres: um panorama das intervenções no Brasil. Saúde e Sociedade, v. 28, n. 1, p. 262-274. DOI: https://doi. org/10.1590/s0104-12902019170995 
BRAGAGNOLO, Regina Ingrid; LAGO, Mara Coelho de Souza; RIFIOTIS, Theophilos. 2015. Estudo dos modos de produção de justiça da Lei Maria da Penha em Santa Catarina. Revista de Estudos Feministas, v.23, n.2, pp.601-617. DOI: https://doi. org/10.159o/0104-026X2015V23n2p601

DEBERT, Guita Grin. 2006. "As Delegacias de Defesa da Mulher: judicialização das relações sociais ou politização da justiça?". In: CORRÊA, Mariza; SOUZA; Érica Renata de (Org.). Vida em família: uma perspectiva comparativa sobre 'crimes de honra'. Campinas: Núcleo de Estudos de Gênero Pagu/Universidade Estadual de Campinas, p. 16-38.

DONZELOT, Jacques. [1977]1986. A Polícia das Famílias. Rio de Janeiro, Graal.

FASSIN, Didier. 2012. Humanitarian Reason: a moral history of the present. Berkeley and Los Angeles, University of California Press.

FOUCAULT, Michel. [1976] 1984.

História da sexualidade I: a vontade de saber. São Paulo, Graal.

FOUCAULT, Michel. [1976] 2000. Em Defesa da sociedade. São Paulo, Martins Fontes.

FOUCAULT, Michel. [1978] 2008.

Segurança, território e população.

São Paulo, Martins Fontes.

COMES, Carla de Castro. 2010. A Lei Maria da Penha e as práticas de construção social da "violência contra a mulher" em Juizado do Rio de Janeiro. Rio de Janeiro, Dissertação de mestrado, Universidade Federal do Rio de Janeiro.

JIMENO, Myriam. 2010. "Emoções e política: a vítima e a construção de comunidades emocionais". Mana-Estudos de Antropologia
Social, n. 16, v. 1, pp. 99-121. https://doi. org/10.1590/So104-93132010000100005

LIMA, Daniel Costa; BUCHELE, Fátima. 2011. Revisão crítica sobre o atendimento a homens autores de violência doméstica e familiar contra as mulheres. Physis: Revista de Saúde Coletiva, v. 21, n. 2. DOI: https://doi. org/10.1590/S0103-73312011000200020

LEITE, Fabiana; LOPES, Paulo Victor Leite. 2013. "Serviços de educação e responsabilização para homens autores de violência contra mulheres: as possibilidades de intervenção em uma perspectiva institucional de gênero". In: LOPES, Paulo Victor; LEITE, Fabiana (Org.). Atendimento a homens autores de violência doméstica: desafios à política pública. Rio de Janeiro: ISER, pp. 129-144.

LOPES, Paulo Victor Leite. 2021. Entre Justaposições e Contraposições: Instrumentos Jurídicos, Discursos e Práticas em Torno da Administração de Homens Autores de Violência Doméstica Contra a Mulher. Antropolítica - Revista Contemporânea De Antropologia,, n. 51. https://doi. org/10.22409/antropolitica2021.i51.a45575

LOPES, Paulo Victor Leite. 2016. Homens Autores de Violência Doméstica: relações de gênero, formas cotidianas de governo e processos de formação de Estado. Rio de Janeiro, Tese de doutorado, Universidade Federal do Rio de Janeiro.

LOPES, Paulo Victor Leite; LEITE, Fabiana (Org.). 2013. Atendimento a homens autores de violência doméstica: desafios à política pública. Rio de Janeiro: ISER.

LUGONES, Maria Gabriela. 2012. Obrando em autos, obrando em vidas: formas e formulas de proteção judicial dos tribunais prevencionais de menores de Córdoba, Argentina, nos começos do século XXI. Rio de Janeiro, E-papers/Laced.

MORAES, Aparecida Fonseca; RIBEIRO, Letícia. 2012. As políticas de combate à 
violência contra a mulher no Brasil e

a "responsabilização" dos "homens autores de violência". Sexualidad, Saludy Sociedad, n. 11, pp.37-58. DOI: https://doi. org/10.1590/S1984-64872012000500003.

MUNIZ, Jacqueline. 1996. Os direitos dos outros e outros direitos: um estudo sobre a negociação de conflitos nas DEAMs/R]. In: SOARES, Luis Eduardo (Org.) Violência e política no Rio de Janeiro. Rio de Janeiro: Iser, Reulme-Dumará, pp. 125-164.

NASCIMENTO, Marcos Antonio Ferreira do. 2001. Desaprendendo o silêncio: uma experiência de trabalho com grupos de homens autores de violência contra a mulher. Rio de Janeiro, Dissertação de mestrado, Instituto de Medicina Social/ Universidade do Estado do Rio de Janeiro.

OLIVEIRA, Isabela Venturoza de. 2016. "Homem é homem": narrativas sobre gênero e violência em um grupo reflexivo com homens denunciados por crimes da Lei Maria da Penha. São Paulo, Dissertação de mestrado, Universidade de São Paulo.

PACHECO DE OLIVEIRA, João Pacheco. 1989.

O Nosso Governo: Os Ticuna e o Regime Tutelar. São Paulo, Marco Zero.
SOUZA LIMA, Antonio Carlos de. 1995. Um grande cerco de paz: poder tutelar, indianidade e formação do Estado no Brasil. Petrópolis, Vozes.

SOUZA LIMA, Antonio Carlos. 2013. "O exercício da tutela sobre os povos indígenas: considerações para o entendimento das políticas indigenistas no Brasil Contemporâneo". Revista de Antropologia, v. 55, n. 2, pp. 781-832. https://doi. org/10.11606/2179-0892.ra.2012.59301.

TEIXEIRA, Carla Costa e SOUZA LIMA, Antonio Carlos de. 2010. "A antropologia da administração e da governança no Brasil: área temática ou ponto de dispersão?". In: DUARTE, Luiz Fernando Dias; MARTINS, Carlos Benedito. (Org.). Horizontes das ciências sociais no Brasil: Antropologia. São Paulo, ANPOCS, pp. 51-95.

VIANNA, Adriana. 2002. Limites da Menoridade: tutela, família e autoridade em julgamento. Rio de Janeiro, Tese de doutorado, Universidade Federal do Rio de Janeiro.

VIANNA, Adriana. 2003. "Quem deve guardar as crianças? Dimensões tutelares da gestão contemporânea da infância". In: SOUZA LIMA, Antonio Carlos de. (Org.). Gestar e Gerir: estudos para uma antropologia da administração pública no Brasil. Rio de Janeiro: Relume-Dumará, p. 271-311.

Recebido em 18 de julho de 2020. Aceito em 22 de abril de 2021. 